\title{
Polymer Processing Using Supercritical Fluid Based Technologies for Drug Delivery and Tissue Engineering Applications
}

\author{
Ana Rita C. Duarte1,2, João F. Mano1,2 and Rui L. Reis ${ }^{1,2}$ \\ 13B's Research Group - Biomaterials, Biodegradables and Biomimetics, \\ University of Minho, Headquarters of the European Institute of Excellence on \\ Tissue Engineering and Regenerative Medicine, AvePark, 4806-909 Taipas, \\ Guimarães, Portugal \\ 2 ICVS/3B's - PT Government Associate Laboratory, Braga/Guimarães, \\ Portugal \\ aduarte@dep.uminho.pt
}

From the use of botanical plants in early human civilizations through synthetic chemistry and biotechnology, drug research has always passionate scientists creating exciting challenges to a large number of researchers from different fields, thus, promoting a collaborative effort between polymer scientists, pharmacologists, engineers, chemists and medical researchers. Worldwide, there is an increasing concern on health care that creates a major opportunity for development of new pharmaceutical formulations. Ageing populations worried about the quality of life in the older years are actively seeking for new, more effective and patient compliant drug delivery devices. This has been the

Supercritical Fluid Nanotechnology: Advances and Applications in Composites and Hybrid Nanomaterials

C. Domingo and P. Subra

Copyright $(2009$ by Pan Stanford Publishing Pte Ltd

www.panstanford.com 
driving force for the continuous growth of the research made on delivery devices, which has become a powerful technique in health care. It has been recognized for long that simple pills or injections may not be the suitable methods of administration of a certain active compound. These medications present several problems and/or limitations, like poor drug bioavailability and systemic toxicity, derived essentially from pharmacokinetic and other carrier limitations and low solubility of the drugs in water. Therefore and to overcome these drawbacks, clinicians recommend frequent drug dosing, at high concentrations, in order to overcome poor drug bioavailability but causing a potential risk of systemic toxicity. Polymer science has open new strategies for drug delivery systems. This Chapter overviews of possible strategies involving polymer modification and processing for controlled drug delivery and drug delivery in tissue engineering.

\subsection{CONTROLLED DRUG DELIVERY SYSTEMS}

A controlled drug release system consists in a drug carrier capable of releasing the bioactive agent in a specific location at a specific rate [1]. The main purpose of these controlled release systems is to achieve a more effective therapy, i.e., a system with a delivery profile that would yield a high blood level of the drug over a long period of time, avoiding large fluctuations in drug concentration and reducing the need of several administrations. Furthermore, these systems often improve the drug performance, provide patient compliance and prolong drug stability. It is of particular interest the key role that materials have in the development of these new drug delivery systems, from polymers, to ceramics or even metals [2-4]. When a pharmaceutical agent is encapsulated within, or attached to, a polymer or lipid, drug safety and efficacy can be greatly improved and new therapies are possible. This has been the driving force for active study of the design of these materials, intelligent delivery systems and approaches for delivery through different administration routes [5]. Drug delivery systems are usually classified according to the mechanism that controls the release of the active compound. There are three primary mechanisms by which active agents can be released from a delivery system: diffusion, degradation (erosion, chemical reaction) or 
swelling (solvent activation) [6,7]. Any or all of these mechanisms may occur in a given release system.

Diffusion controlled systems are the most common ones. Two types of diffusion controlled systems have been developed, presenting the same basic principle: diffusion occurs when a drug or other active agent passes through the polymer that forms the controlled-release device. One type of diffusion-controlled release system corresponds to a reservoir device in which the bioactive compound (drug) forms a core surrounded by an inert diffusion barrier. These systems include membranes, capsules, microcapsules, liposomes and hollow fibbers. In this case, drug diffusion through the polymer matrix is the rate limiting step, and release rates are determined by the choice of polymer and its consequent effect on the diffusion and partition coefficient of the drug to be released [7]. The second type is a monolithic device in which the active substance is dispersed or dissolved in an inert polymer. These are possibly the most common devices for controlled drug delivery since they are relatively easy to fabricate and there is no danger of an accidental high dosage that could result from the rupture of the membrane on the reservoir device. The dosage release properties may be dependent upon the solubility of the drug in the polymer matrix, or in the case of porous matrixes also the tortuosity of the network, dependent on whether the drug is dispersed or dissolved in the polymer [8].

Biodegradable materials degrade within the body as a result of natural biological processes, eliminating the need to remove a drug delivery system after release of the active agent has been completed. Chemically controlled systems can be achieved using bioerodible or pendant chain systems, i.e., either by polymer degradation or cleavage of the drug from the polymer [9]. Polymer degradation can be defined as the conversion of a material that is insoluble in water into metabolites that are water soluble. In ideal bioerodible systems, the drug is homogeneously distributed in the polymer, just like in the matrix devices. As the polymer surrounding the drug is eroded, the drug is released. In the case of pendant chain system, the drug is covalently bound to the polymer and it is released by bond scission due to water or enzymes. Furthermore, degradation may take place through bulk hydrolysis, in which the polymer degrades in a fairly uniform manner throughout the matrix or it may occur only at the surface of the polymer, 

and Tissue Engineering Applications

resulting in a release rate that is proportional to the surface area of the drug delivery system [10].

\subsubsection{Particle formation/encapsulation}

Many technologies have been proposed to prepare polymeric particles for controlled drug release [11,12]. In particular, supercritical fluid technology presents many possibilities for particle formation and/or encapsulation. The differences between the processing techniques that have been reported are a result of the interactions and phase behavior of the active compounds with the supercritical fluid (SCF) [13-15]. A brief description of the main characteristics of each process is listed in Table 12.1.

Table 12.1. Summary of the supercritical fluid techniques for particle formation and/or encapsulation.

Rechnique
$\begin{gathered}\text { (Rapid Expansion from } \\ \text { Supercritical Solutions) }\end{gathered}$ $\begin{gathered}\text { SAS } \\ \text { (Supercritical Anti-Solvent) } \\ \text { RCF }\end{gathered}$

In a Rapid Expansion from Saturated Solutions (RESS) process, the supercritical fluid acts as a solvent. In this technique, the active compound is dissolved in the supercritical fluid phase and the solution is expanded into a low pressure vessel. Although this process is highly advantageous as no organic solvents are involved it requires high ratios 
gas/solute and high operating pressure and temperature, as the solubility of the compounds is usually low. The preparation of delivery systems using this technique is limited by the poor solubility of polymers in the fluid phase, and therefore it has not been widely used in the preparation of controlled delivery systems [15].

Supercritical Anti-Solvent (SAS) technique uses the supercritical fluid as an anti-solvent, taking advantage of the poor solubility of high molecular weight or polar compounds in SCFs. In this process the compound or mixture of compounds are dissolved in an organic solution and the SCF acts as an anti-solvent promoting the precipitation of the solute. The principle of the process is to decrease the solvent power of the liquid by the addition of an anti-solvent in which the solute is insoluble. This process broadens the applicability of the technique for the development of controlled drug delivery systems as numerous active compounds and polymers may be processed in a single step operation after determining the appropriate solvent for the mixture. Lopez-Periago et al. report the preparation of PMMA particles loaded with triflusal and the preparation of poly-lactic acid fibers by supercritical anti-solvent $[16,17]$. Furthermore SAS extends the applicability of supercritical fluid technology to the development of encapsulated systems. Encapsulation processes by supercritical precipitation techniques have been reviewed by Cocero et al. in a manuscript where different techniques and the mechanisms behind them are discussed in detail [18]. Hybrid materials can be prepared by co-precipitation of the active compound and the coating material. In this case a physical mixture of the active compound and drug carrier, such as polymer, is obtained and the interactions between them lead to a controlled release of the pharmaceutical agent. On the other hand, the possibility to co-precipitate different solutions through a co-axial nozzle has been explored and it is reported as Supercritical Enhanced Dispersion of Solutions (SEDS) in different papers [19-21]. In this case, the active compound is injected through the inner nozzle capillary, the polymer is injected through the middle capillary and the anti-solvent flows through the outer part. This nozzle design offers the possibility to precipitate particles of the core material in the matrix of the coating material, which nucleates around the first particles to be precipitated forming a thin shell or a capsule around the active ingredient. The initial concentrations of both active ingredient and carrier, as well as the flow ratio of the two solutions, will determine the 
final morphology of the particles as well as the encapsulation efficiency. SAS processing can be carried out under mild operating conditions, i.e., near ambient temperatures. This technique allows the production of particles in the nanometer size and the particle size and morphology can be easily controlled. The main disadvantages are related with the difficulty in scaling up the process, as different thermodynamic and hydrodynamic effects need to be taken into account. The use of organic solvent represents also a disadvantage of the process, since it has to be rigorously controlled in the case of pharmaceutical applications and may be present in residual amounts in the product.

In particles from gas saturated solutions (PASS) the supercritical fluid acts as a solute [22]. In this technique, the SCF is dissolved in the melted solution and the solution is expanded into a low pressure vessel. This method does not require the use of organic solvents, it can be easily scaled-up and has a high production capacity. Nonetheless, the high temperatures required to process some polymers may compromise its application for the processing of thermosensitive active compounds. For example, protein loaded lipid micro particles were produced and reported by Salas et al. [23]. Casettari et al. report the use of PASS for the development of mucoadhesive particles form chitosan and poly-lactic acid for gastrointestinal drug delivery [24]. Falconer et al. present a multivariate study on the effect of different operating conditions for the preparation of progesterone loaded gelucire particles and the results demonstrate that not only the independent variables of pressure and temperature influence the result but also the interaction between them influence the yield of the process [25]. Other examples, such as the encapsulation of caffeine or trans-chalcone in lipid carriers have been presented by Sousa et al. [36,27]. Garcia-Gonzalez et al. report the encapsulation of agents with different polarity by PASS and the encapsulation of inorganic particles for topical administration [28,29].

\subsubsection{Impregnation}

The preparation of drug release products often necessitates the use of a mobile phase to dissolve and carry the drug component, which also swells and stretches the polymer matrix, facilitating the diffusion of the drug, and increasing the rate of impregnation. Conventionally, the 
preparation of these systems involves three steps: solubilization of the pharmaceutical in an appropriate solvent, diffusion of the pharmaceutical through the polymer and elimination of the residual solvent. The dispersion of active compounds within a finished or semifinished matrix, that will serve as carrier takes advantage of the solubility of pharmaceutical compounds in supercritical conditions. The drug is dissolved in carbon dioxide and diffuses into the bulk of the matrix, when the system is depressurized the gas rapidly diffuses out of the polymer, leaving the drug absorbed or entrapped within the polymeric matrix and warranting the complete removal of solvent, without exposing polymers and drugs to high temperatures, which may degrade them. In Fig. 12.1, a schematic diagram of the process is presented.

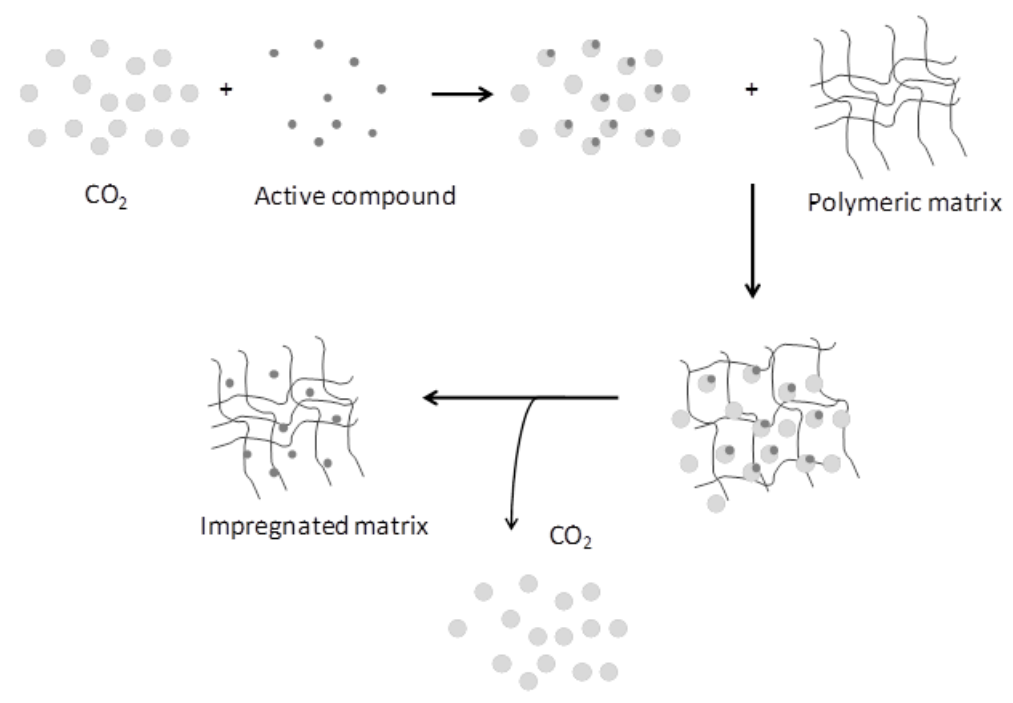

Figure 12.1. Schematic representation of the supercritical fluid impregnation process.

Supercritical fluid impregnation is a process that requires the knowledge of the interactions between polymer-active compoundsupercritical fluid. Kazarian et al. [30-33] distinguish two mechanisms of impregnation assisted by supercritical fluids. The first mechanism corresponds to a simple deposition of the compound when the fluid leaves the swollen matrix. In this case, the solute is solubilized in carbon 
dioxide and the polymer is exposed to this solution for a predetermined period followed by depressurization of the system. When the system is depressurised, carbon dioxide molecules quickly leave the polymer matrix, leaving the solute trapped inside. As reported by Kazarian et al., this mechanism concerns mostly solutes with a relatively high solubility in the fluid and it is specific to impregnations carried out on a matrix subjected to swelling upon exposure to supercritical fluids. The second effect, not specific to supercritical fluids, corresponds to chemical interactions (like van der Walls interactions) between the solute and the matrix, which would favor the preferential partitioning of the solute with the polymer phase [32].

Kikic and co-workers reviewed in 2003 the potential applications of polymer impregnation [34]. Since then, this technique has been employed in the preparation of a large number of drug delivery devices, which can be administered through different routes. Ophaltmic drug delivery systems have been developed for the treatment of diseases as glaucoma. Braga et al. report the development of hydrogels as ophthalmic drug delivery systems in which chitosan derivatives were impregnated with flurbiprofen and timolol maleate [35]. The same research group describes the preparation of therapeutic contact lenses after the impregnation of commercially available contact lenses with different active compounds [36-39]. The authors report that supercritical fluid impregnation does not compromise the integrity of the contact lenses, which provides major advantages over conventional impregnation techniques. The development of intraocular drug delivery systems has also gained attention especially in which concerns the postoperative treatment of cataract surgery [40-42]. The preparation of transdermal drug delivery systems has also been reported in the literature. In this application the possibility to homogeneously disperse the active compound in the matrix, the ease of diffusion of the drug into the bulk of the material and the fact that no organic solvents are used is particularly relevant. In the work of Argemi et al. [43], transdermal patches were impregnated with naproxen. The membranes prepared have shown a sustainable drug release up to $24 \mathrm{~h}$. The preparation of wound dressings impregnated with two natural bioactive compounds is another example of a drug delivery device prepared using supercritical solvent impregnation reported in the literature [44]. 
Supercritical impregnation of polymeric matrices in the form of powders has also been widely explored. Examples of the systems studied and reported in the past few years are the case of poly(vinylpyrrolidone) impregnated with ketoprofen [45], hydroxypropylmethyl cellulose impregnated with indomethacin [46], impregnation of ibuprofen and timolol maleate in poly-( $\varepsilon$-caprolactone) [47,48], impregnation of paclitaxel, roxithromycin and 5-fluorouracil in poly-(lactic acid) particles [49-51], among others. Duarte et al. have compared the release of naproxen from ethylcellulose/methylcellulose particles prepared by different techniques [52]. Although in some cases the yield of supercritical fluid impregnation is not as high as the yield achieved by conventional techniques, such as solvent evaporation or soaking, the technique still presents major advantages.

\subsubsection{Molecular imprinting}

Molecular imprinting is a technique that allows the design of a precise macromolecular structure able to recognize specific molecules [53,54]. The mechanism underlying molecular imprinting is similar to the enzyme substrate concept. The principle of preparation of molecular imprinted polymers (MIPs) is schematically represented in Fig. 12.2.

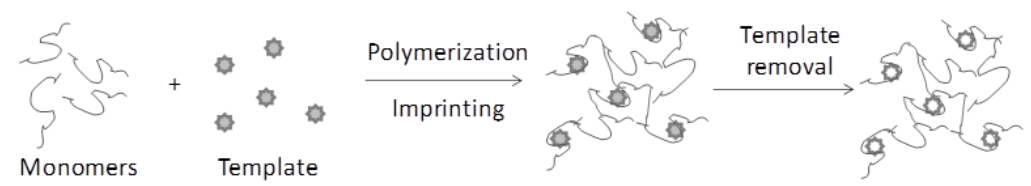

Figure 12.2. Schematic representation of the preparation of moleculary imprinted polymers (MIPs).

A network with specific conformational and structural sites is formed by polymerization and cross-linking of the monomer around the template. After polymerization, the template is leached out, providing macromolecular cavities for the entrapment of the particular molecule used. The envisaged applications for this technology greatly surpass the pharmaceutical field and encompass analytical applications, such as biosensors, immunoassays, separation media and affinity supports among others. Although the mechanism is relatively simple the optimization of is more complicated due to the contribution of several 
variables involved in the process, such as the functional monomer(s), the type of cross-linker, the ratio between monomer and cross-linker and the ratio between monomer and template.

The polymerization can be carried out under supercritical conditions, using carbon dioxide as a reaction media or following conventional polymerization routes. Duarte et al. have reported the preparation of molecularly imprinted poly(diethylene glycol dimethacrylate) with salicylic and acetylsalicylic acid [55]. Results indicate that the amount of drug impregnated is significantly higher when a template molecule is present during the polymerization step. Other examples of MIPs have been reported following the same approach and using propanolol, ibuprofen or flufenamic acid as model drugs [56-58]. Flufenamic acid was impregnated in a thermoresponsive drug delivery system, based on poly-isopropylacrylamide that was prepared using the molecular imprinting approach. This work represents a step forward in the development of complex delivery systems using clean technologies. In another work, Kobayashi et al. report the preparation of an uracil imprinted membrane of poly(styrene-co-maleic acid), demonstrating the flexibility of the technology for the preparation of different types of substrates [59].

\subsubsection{Externally triggered delivery devices}

Smart drug delivery systems have been object of intense research [60-64]. The ability to release a bioactive compound according to a physiological need, in a spatio-temporal controlled manner may be the answer to avoid fluctuations and high concentrations of drug, which induce undesired side-effects. The possibility to trigger the release of the drug by external stimuli would be highly beneficial [62,65]. Several mechanisms have been described in the literature. Table 12.2 presents the mechanisms of action behind several external stimuli. Temperature sensitive drug delivery systems are by far the most widely studied. Particularly interesting are hydrogels containing poly $(\mathrm{N}-$ isopropylacrylamide) (PNIPAAm). Hydrogels based on PNIPAAm present various applications from drug delivery, cell encapsulation and cell culture surfaces. This polymer presents, in aqueous solutions, a low critical solution temperature (LCST) around $32{ }^{\circ} \mathrm{C}$, which makes it 
extremely interesting for applications in the biomedical field. Below the LCST, in aqueous solutions, it presents a flexible extended coil conformation, which makes it hydrophilic. Close to the LCST it becomes hydrophobic as polymer chains collapse and aggregate into a globular structure. Furthermore, copolymerization of NIPAAm with other monomers may change the overall hydrophilicity of the polymer. Conventional methods of polymerization involve the use of organic solvents and often require the use of cross-linking agents, which might be toxic. Temtem et al. have reported the successful polymerization of PNIPAAm in supercritical carbon dioxide [66]. The process proposed allows the in-situ polymerization of PNIPAAm, leading to the development of smart-drug delivery devices in a single step process [67].

Table 12.2. Mechanism of action of different stimuli used as triggers for controlled drug release.

\begin{tabular}{ll}
\hline External stimuli & Mechanism of action \\
\hline Thermal & $\begin{array}{l}\text { Change in temperature - change in polymer-polymer and water- } \\
\text { polymer interactions - change in polymer conformation and } \\
\text { solubility - change in swelling - drug release } \\
\text { Change in pH-swelling-drug release }\end{array}$ \\
$\begin{array}{l}\text { Change in ionic strength-change concentration of ions inside drug } \\
\text { delivery device - change in swelling - drug release }\end{array}$ \\
Ionic strength & $\begin{array}{l}\text { Electron donating compounds - formation of charge/transfer } \\
\text { complex- change in swelling - drug release }\end{array}$ \\
Chemical species & $\begin{array}{l}\text { Change in swelling of the matrix - promotes enzyme activity over } \\
\text { the substrate - degradation of the substrate by enzymatic cleavage }\end{array}$ \\
Enzyme mediated & - drug release \\
& $\begin{array}{l}\text { Applied magnetic field - changes pores in the matrix - change in } \\
\text { swelling - drug release } \\
\text { Applied electrical field - membrane charging - electrophoresis of } \\
\text { Magnetic }\end{array}$ \\
charged drug - change in swelling - drug release \\
Electrical & Ultrasound irradiation - temperature increase - drug release \\
Ultrasound irradiation &
\end{tabular}

Certain polysaccharides and polymers respond to $\mathrm{pH}$ changes as it is the case of chitosan, alginate, hyaluronic acid as examples of natural polymers and polyacrylic acid as a synthetic $\mathrm{pH}$ responsive polymer [68]. Chitosan owes its $\mathrm{pH}$ sensitive behavior to the large amount of amino groups present in its chains and swells in acidic $\mathrm{pH}$, while for polyacrylic acid, on the other hand, due to the presence of acidic groups swells in basic media. Temtem et al. refer the preparation of a dual 

and Tissue Engineering Applications

stimuli responsive matrix, based on chitosan and PNIPAAm [69]. Chitosan is a $\mathrm{pH}$ responsive polymer, while PNIPAAm is thermosensitive. The results demonstrate the possibility to control polymer swelling by either $\mathrm{pH}$ or temperature, and drug release can be modulated according to the different stimuli applied. Other examples of externally triggered pulse-wise drug delivery devices have been developed for specific applications, nonetheless supercritical fluid technology has, to our knowledge, not yet been reported in the development of such systems.

\subsection{DRUG DELIVERY IN TISSUE ENGINEERING APPLICATIONS}

The concept of tissue engineering has long surpassed the idea of a merely inert support for cell attachment and growth. Tissue engineering is a promising therapeutic approach that involves the edges of a triangle in which, materials, active principles and cells all play an important role ( Fig. 12.3) [12,70-72].

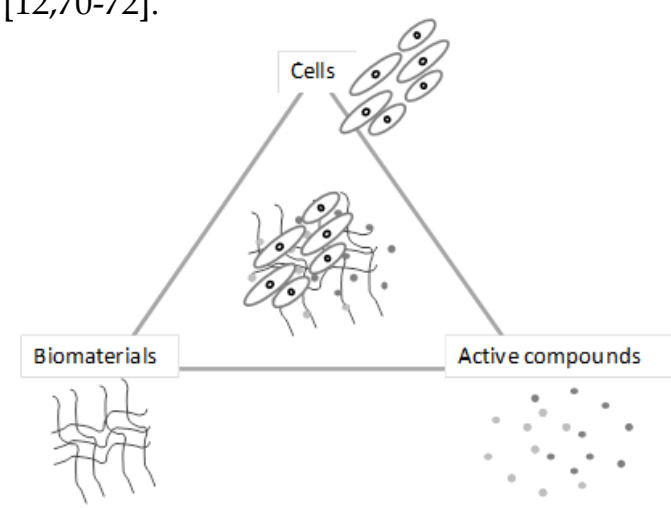

Figure 12.3. Tissue engineering: a combinatory approach of biomaterials, cells and active compounds.

In this sense, the preparation of delivery systems able to sustain the release of biologically active molecules is a major challenge. Within the tissue engineering field, not only a controlled release needs to be achieved but the polymer architecture requires very particular features for each given tissue [73]. 3D architectures or scaffolds should present adequate surface properties, both chemically and topographically, as 
these characteristics will ultimately dictate cell adhesion to the surface. Furthermore, they should present adequate porosity, mean pore size and interconnectivity between the pores to promote cell penetration and assure oxygen and nutrient diffusion into the bulk of the matrix, as well as waste retrieval. Matrices must also have appropriate mechanical properties to withstand mechanical forces and maintain physical integrity, the materials must be biocompatible, and the degradation products non-cytotoxic.

The major challenge in tissue engineering arises, in the optimization of polymer processing techniques [74]. A variety of different processing techniques have been developed and include fibre bonding, freeze drying, solvent casting and particle leaching, wet spinning, particle aggregation, electrospinning, 3D potting and supercritical fluid technology among others ( Fig. 12.4) [75]. The choice of the most suitable polymer processing technique depends greatly on the characteristics of the polymer itself, particularly their solubility in aqueous or organic solutions and their thermal properties as these will ultimately determine the feasibility to successfully produce matrices with the desired features. Processing thermosensitive bioactive compounds requires, however, the use of mild processing conditions and the reduction of the amount of organic solvents used [76,77]. This presents an increase challenge in materials processing for tissue engineering and regenerative medicine.

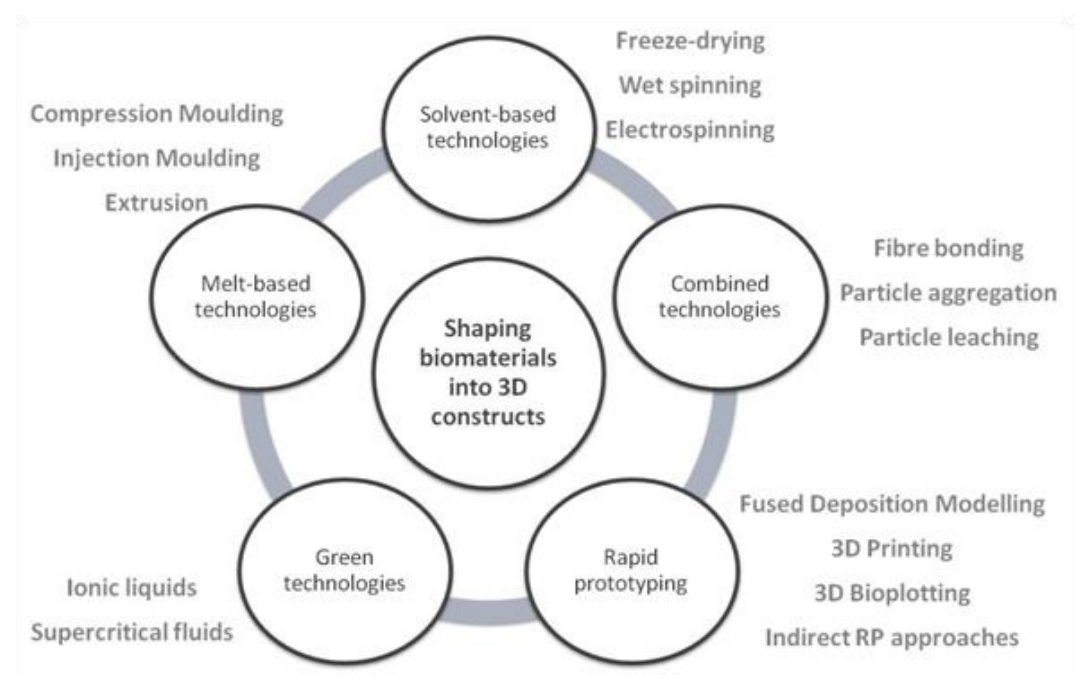


and Tissue Engineering Applications

Figure 12.4. Summary of different polymer processing methodologies employed in scaffold fabrication for tissue engineering and regenerative medicine.

The application of green technologies for the preparation of structures for tissue engineering has gained much attention in the past ten years and a number of publications have been reported describing a variety of different techniques aiming to pursue the development of a single step technology able to produce a material with all the desired properties. From the use of carbon dioxide as a drying agent in supercritical fluid drying, to the use of carbon dioxide as a plasticizing agent in gas foaming and sintering or the use of carbon dioxide as an anti-solvent in the supercritical assisted phase inversion method, almost all encounter a way to satisfy most of the characteristics requested. A summary of the features of the different technologies and some examples of drug delivery systems for tissue engineering and regenerative medicine applications are listed in Table 12.3 [78-88]. Hydrogel foaming is a more recent technique which has been explored for the preparation of porous scaffolds and in this process hydrogels foaming involves the dissolution of carbon dioxide in the water phase present on the hydrogel which will promote foaming of the structure upon depressurization $[89,90]$. Sintering is a technique which occurs at near critical conditions and relies on the slight plasticization of the polymer particles which are fused together, creating a 3D environment [91,92]. Although these techniques have not yet been reported for the preparation of drug delivery systems, their mild processing conditions foresee interesting developments in this field, especially in which concerns the impregnation of proteins, growth factors and cells. 
Table 12.3. Summary of different supercritical-based techniques used in the preparation of drug delivery systems in tissue engineering applications.

\begin{tabular}{|c|c|c|}
\hline Technique & Principle & Examples of drug delivery systems prepared \\
\hline Foaming & $\begin{array}{l}\text { The polymer is exposed to } \\
\text { carbon dioxide at the saturation } \\
\text { pressure and temperature, } \\
\text { which plasticizes the polymer } \\
\text { and reduces the glass transition } \\
\text { temperature. Upon } \\
\text { depressurization, } \\
\text { thermodynamic instability } \\
\text { causes supersaturation of the } \\
\text { carbon dioxide dissolved in the } \\
\text { polymeric matrix, and hence, } \\
\text { nucleation of the cells occurs. }\end{array}$ & $\begin{array}{l}\text { Poly(d,l-lactide) and poly(d,l-lactide-co- } \\
\text { glycolide) impregnated with indomethacin [78] } \\
\text { Poly(methyl methacrylate)-poly(L-lactic acid) } \\
\text { foams loaded with ibuprofen [79] } \\
\text { Poly(D,L-lactide-co-glycolide) foams with } \\
\text { encapsulated growth factors [80] } \\
\text { 3D architectures of poly(D,L-lactide-co- } \\
\text { glycolide) as vehicles for DNA delivery [81] } \\
\text { Vascular endothelial growth factor encapsulated } \\
\text { in PLGA scaffolds [82,83] }\end{array}$ \\
\hline $\begin{array}{l}\text { Phase } \\
\text { inversion }\end{array}$ & $\begin{array}{l}\text { The polymer is dissolved in an } \\
\text { organic solvent and placed in } \\
\text { contact with a non-solvent } \\
\left(\mathrm{CO}_{2}\right) \text {, which causes the } \\
\text { solution to be phase separated, } \\
\text { creating a 3D porous structure. }\end{array}$ & $\begin{array}{l}\text { Starch-poly-lactic acid blend impregnated with } \\
\text { dexamethasone [84] } \\
\text { Poly(vinylidene fluoride-co- } \\
\text { hexafluoropropylene) loaded with amoxicillin } \\
\text { [85] } \\
\text { Poly-methylmethacrylate loaded with amoxicilin } \\
\text { [86] }\end{array}$ \\
\hline Drying & $\begin{array}{l}\text { Supercritical drying is a drying } \\
\text { technique which does not } \\
\text { compromise the integrity of the } \\
\text { structure as there are no phase } \\
\text { boundaries, i.e., phase } \\
\text { transitions involved in the } \\
\text { process. }\end{array}$ & $\begin{array}{l}\text { Chitosan matrices impregnated with } \\
\text { camptothecin and griseofulvin [87] } \\
\text { Chitin scaffolds loaded with dexamethasone [88] }\end{array}$ \\
\hline
\end{tabular}

\subsection{CONCLUSIONS}

The preparation of drug delivery systems is intimately related with polymer modification and the design of new processes able to produce systems that meet most of the requirements of an ideal delivery system. Different techniques, from particle formation, impregnation and polymerization have been explored and are reported in the literature. In the future the combination and integration of different techniques may see exciting perspectives as a single technique may not be enough for the 
development of a drug delivery system which meets all the required features. The integration of different technologies could provide interesting developments in shaping biomaterials into various constructs, opening a wide range of opportunities for the preparation of enhanced polymeric materials as structural supports for drug delivery.

\section{Acknowledgements}

The authors acknowledge the funding from the European Union Seventh Framework Programme (FP7/2007-2013) under grant agreement number REGPOT-CT2012-316331-POLARIS and from the project "Novel smart and biomimetic materials for innovative regenerative medicine approaches" RL1 - ABMR - NORTE-01-0124-FEDER-000016 cofinanced by North Portugal Regional Operational Programme (ON.2 - O Novo Norte), under the National Strategic Reference Framework (NSRF), through the European Regional Development Fund (ERDF).

\section{References}

1. Peppas, N. A. (2013). Historical perspective on advanced drug delivery: How engineering design and mathematical modeling helped the field mature, Adv. Drug Deliver. Rev., 65, pp. 5-9.

2. Mehnert, W. and Mader, K. (2012). Solid lipid nanoparticles production, characterization and applications, Adv. Drug Deliver. Rev., 64, pp. 83-101.

3. Park, J. S., Lee, J. H., Shin, H. S., Lee, T. W., Kim, M. S., Khang, G., Rhee, J. M., Lee, H. K. and Lee, H. B. (2007). Biodegradable polymer microspheres for controlled drug release, Tissue Eng. Regen. Med., 4, pp. 347-359.

4. Freiberg, S. and Zhu, X. (2004).Polymer microspheres for controlled drug release, Int. J. Pharmaceut., 282, pp. 1-18.

5. Langer, R. (1990). New methods of drug delivery, Science, 249, pp. 1527-1533.

6. Siepmann, J. and Peppas, N. A. (2012). Modeling of drug release from delivery systems based on hydroxypropyl methylcellulose (HPMC), Adv. Drug Deliver. Rev., 64, pp. 163-174.

7. Siepmann, J. and Gopferich, A. (2001). Mathematical modeling of bioerodible, polymeric drug delivery systems, Adv. Drug Deliver. Rev., 48, pp. 229-247.

8. Pillai, O. and Panchagnula, R. (2001). Polymers in drug delivery, Curr. Opin. Chem. Biol., 5, pp. 447-451. 
9. Nair, L. S. and Laurencin, C. T. (2007). Biodegradable polymers as biomaterials, Prog. Polym. Sci., 32, pp. 762-798.

10. Gopferich, A. (1996). Mechanisms of polymer degradation and erosion, Biomater., 17, pp. 103-114.

11. Lima, A. C., Sher, P. and Mano, J. F. (2012). Production methodologies of polymeric and hydrogel particles for drug delivery applications, Expert. Opin. Drug. Del., 9, pp. 231-248.

12. Santo, V. E., Gomes, M. E., Mano, J. F. and Reis, R. L. (2013). Controlled release strategies for bone, cartilage, and osteochondral engineering-Part I: Recapitulation of native tissue healing and variables for the design of delivery systems, Tissue Eng. Part. B-Re., 19, pp. 308-326.

13. Mishima, K. (2008). Biodegradable particle formation for drug and gene delivery using supercritical fluid and dense gas, Adv. Drug Deliver. Rev., 60, pp. 411-432.

14. Qiao, J. C., Ha, X. L., Guan, P., Zhao, Y. and Tian, W. (2008). Preparation and development of pharmaceutical microcapsules, Prog. Chem., 20, pp. 171-181.

15. Yeo, S. D. and Kiran, E. (2005). Formation of polymer particles with supercritical fluids: A review, J. Supercrit. Fluids, 34, pp. 287-308.

16. Lopez-Periago, A. M., Vega, A., Subra, P., Argemi, A., Saurina, J., GarciaGonzalez, C. A. and Domingo, C. (2008). Supercritical $\mathrm{CO}_{2}$ processing of polymers for the production of materials with applications in tissue engineering and drug delivery, J. Mater. Sci., 43, pp. 1939-1947.

17. Andanson, J. M., Lopez-Periago, A. M., Garcia-Gonzalez, C. A., Domingo, C. and Kazarian, S. G. (2009). Spectroscopic analysis of triflusal impregnated into PMMA from supercritical $\mathrm{CO}_{2}$ solution, Vib. Spectrosc., 49, pp. 183-189.

18. Cocero, M. J., Martin, A., Mattea, F. and Varona, S. (2009). Encapsulation and co-precipitation processes with supercritical fluids: Fundamentals and applications, J. Supercrit. Fluids, 47, pp. 546-555.

19. Franceschi, E., de Cesaro, A. M., Feiten, M., Ferreira, S. R. S., Dariva, C., Kunita, M. H., Rubira, A. F., Muniz, E. C., Corazza, M. L. and Oliveira, J. V. (2008). Precipitation of beta-carotene and PHBV and co-precipitation from SEDS technique using supercritical $\mathrm{CO}_{2}$, J. Supercrit. Fluids, 47, pp. 259-269.

20. He, W. Z., Jiang, Z. H., Suo, Q. L. and Li, G. M. (2010). Mechanism of dispersing an active component into a polymeric carrier by the SEDS-PA process, J. Mater. Sci., 45, pp. 467-474.

21. Wang, Y. L., Dave, R.N. and Pfeffer, R. (2004). Polymer coating/encapsulation of nanoparticles using a supercritical anti-solvent process, J. Supercrit. Fluids, 28, pp. 85-99.

22. Elvassore, N. Flaibani, M., Bertucco, A. and Caliceti, P. (2003). Thermodynamic analysis of micronization processes from gas-saturated solution, Ind. Eng. Chem. Res., 42, pp. 5924-5930. 
23. Salmaso, S., Elvassore, N., Bertucco, A. and Caliceti, P. (2009). Production of solid lipid submicron particles for protein delivery using a novel supercritical gas-assisted melting atomization process, J. Pharm. Sci. US, 98, pp. 640-650.

24. Casettari, L., Castagnino, E., Stolnik, S., Lewis, A., Howdle, S. M. and Illum, L. (2011). Surface characterisation of bioadhesive PLGA/chitosan microparticles produced by supercritical fluid technology, Pharm. Res. Dordr., 28, pp. 1668-1682.

25. Falconer, J. R., Wen, J. Y., Zargar-Shoshtari, S., Chen, J. J., Mohammed, F., Chan, J. D. and Alany, R. G. (2012). The effects of supercritical carbon dioxide processing on progesterone dispersion systems: a multivariate study, Aaps. Pharmscitech., 13, pp. 1255-1265.

26. de Sousa, A. R. S., Silva, R., Tay, F. H., Simplicio, A. L., Kazarian, S. G. and Duarte, C. M. M. (2009). Solubility enhancement of trans-chalcone using lipid carriers and supercritical $\mathrm{CO}_{2}$ processing, J. Supercrit. Fluids, 48, pp. 120-125.

27. de Sousa, A. R. S., Simplicio, A. L., de Sousa, H. C. and Duarte, C. M. M. (2007). Preparation of glyceryl mono stearate-based particles by PGSS((R)) Application to caffeine, J. Supercrit. Fluids, 43, pp. 120-125.

28. Garcia-Gonzalez, C. A., Argemi, A., de Sousa, A. R. S., Duarte, C. M. M., Saurina, J. and Domingo, C. (2010). Encapsulation efficiency of solid lipid hybrid particles prepared using the PGSS (R) technique and loaded with different polarity active agents, J. Supercrit. Fluids, 54, pp. 342-347.

29. Garcia-Gonzalez, C. A., de Sousa, A. R. S., Argemi, A., Periago, A. L., Saurina, J., Duarte, C. M. M. and Domingo, C. (2009). Production of hybrid lipid-based particles loaded with inorganic nanoparticles and active compounds for prolonged topical release, Int. J. Pharmaceut., 382, pp. 296304.

30. Kazarian, S. G. and Martirosyan, G. G. (2002). Spectroscopy of polymer/drug formulations processed with supercritical fluids: in situ ATRIR and Raman study of impregnation of ibuprofen into PVP, Int. J. Pharmaceut., 232, pp. 81-90.

31. Kazarian, S. G., Briscoe, B. J. and Lawrence, C. J. (1999). Supercritical enhanced processing, Polym. Process Eng., 99, pp. 28-36.

32. Kazarian, S. G., Vincent, M. F., West, B. L. and Eckert, C. A. (1998). Partitioning of solutes and cosolvents between supercritical $\mathrm{CO}_{2}$ and polymer phases, J. Supercrit. Fluids, 13, pp. 107-112.

33. Kazarian, S. G., West, B. L., Vincent, M. F. and Eckert, C. A. (1997). Spectroscopic method for in situ analysis of supercritical fluid extraction and impregnation of polymeric matrices, Am. Lab., 29, pp. B18. 
34. Kikic, I. and Vecchione, F. (2003). Supercritical impregnation of polymers, Curr. Opin. Solid. State Matter, 7, pp. 399-405.

35. Braga, M. E. M., Pato, M. T. V., Silva, H. S. R. C., Ferreira, E. I., Gil, M. H., Duarte, C. M. M. and de Sousa, H. C. (2008). Supercritical solvent impregnation of ophthalmic drugs on chitosan derivatives, J. Supercrit. Fluids, 44, pp. 245-257.

36. Braga, M. E. M., Yanez, F., Alvarez-Lorenzo, C., Concheiro, A. Duarte, C. M. M., Gil, M. H. and de Sousa, H. C. (2010). Improved drug loading/release capacities of commercial contact lenses obtained by supercritical fluid assisted molecular imprinting methods, J. Control. Release, 148, pp. E102E104.

37. Costa, V. P., Braga, M. E. M., Duarte, C. M. M., Alvarez-Lorenzo, C., Concheiro, A., Gil, M. H. and de Sousa, H. C. (2010). Anti-glaucoma drugloaded contact lenses prepared using supercritical solvent impregnation, $J$. Supercrit. Fluids, 53, pp. 165-173.

38. Costa, V. P., Braga, M. E. M., Guerra, J. P., Duarte, A. R. C., Duarte, C. M. M., Leite, E. O. B., Gil, M. H. and de Sousa, H. C. (2010). Development of therapeutic contact lenses using a supercritical solvent impregnation method, J. Supercrit. Fluids, 52, pp. 306-316.

39. Braga, M. E. M., Costa, V. P., Pereira, M. J. T., Fiadeiro, P. T., Gomes, A. P. A. R., Duarte, C. M. M. and de Sousa, H. C. (2011). Effects of operational conditions on the supercritical solvent impregnation of acetazolamide in Balafilcon A commercial contact lenses, Int. J. Pharmaceut., 420, pp. 231-243.

40. Masmoudi, Y., Ben Azzouk, L., Forzano, O., Andre, J. M. and Badens, E. (2011). Supercritical impregnation of intraocular lenses, J. Supercrit. Fluids, 60, pp. 98-105.

41. Gonzalez-Chomon, C., Braga, M. E. M., de Sousa, H. C., Concheiro, A. and Alvarez-Lorenzo, C. (2012). Antifouling foldable acrylic IOLs loaded with norfloxacin by aqueous soaking and by supercritical carbon dioxide technology, Eur. J. Pharm. Biopharm., 82, pp. 383-391.

42. Duarte, A. R. C., Simplicio, A. L., Vega-Gonzalez, A., Subra-Paternault, P., Coimbra, P., Gil, M. H., de Sousa, H. C. and Duarte, C. M. M. (2007). Supercritical fluid impregnation of a biocompatible polymer for ophthalmic drug delivery, J. Supercrit. Fluids, 42, pp. 373-377.

43. Argemi, A., Ellis, J. L., Saurina, J. and Tomasko, D. L. (2011). Development of a polymeric patch impregnated with naproxen as a model of transdermal sustained release system, J. Pharm. Sci. US, 100, pp. 992-1000.

44. Dias, A. M. A., Braga, M. E. M., Seabra, I. J., Ferreira, P., Gil, M. H. and de Sousa, H. C. (2011). Development of natural-based wound dressings impregnated with bioactive compounds and using supercritical carbon dioxide, Int. J. Pharmaceut., 408, pp. 9-19. 
45. Manna, L., Banchero, M., Sola, D., Ferri, A., Ronchetti, S. and Sicardi, S. (2007). Impregnation of PVP microparticles with ketoprofen in the presence of supercritical $\mathrm{CO}_{2}$, J. Supercrit. Fluids, 42, pp. 378-384.

46. Gong, K., Rehman, I. U. and Darr, J. A. (2008). Characterization and drug release investigation of amorphous drug-hydroxypropyl methylcellulose composites made via supercritical carbon dioxide assisted impregnation, $J$. Pharmaceut. Biomed., 48, pp. 1112-1119.

47. Natu, M. V., Gil, M. H. and de Sousa, H. C. (2008). Supercritical solvent impregnation of poly(epsilon-caprolactone)/poly(oxyethylene-boxypropylene-b-oxyethylene) and poly(epsiloncaprolactone)/poly(ethylene-vinyl acetate) blends controlled release applications, J. Supercrit. Fluids, 47, pp. 93-102.

48. Yoganathan, R., Mammucari, R. and Foster, N. R. (2010). Impregnation of ibuprofen into polycaprolactone using supercritical carbon dioxide, J. Phys.: Conf. Ser., 215, pp. 1-5 (012087).

49. Yoda, S., Sato, K. and Oyama, H. T. (2011). Impregnation of paclitaxel into poly(DL-lactic acid) using high pressure mixture of ethanol and carbon dioxide, Rsc. Adv., 1, pp. 156-162.

50. Yu, J. P., Guan, Y. X., Yao, S. J. and Zhu, Z. Q. (2011). Preparation of roxithromycin-loaded poly(L-lactic acid) films with supercritical solution impregnation, Ind. Eng. Chem. Res., 50, pp. 13813-13818.

51. Zhan, S. P., Chen, C., Zhao, Q. C., Wang, W. J. and Liu, Z. J. (2013). Preparation of 5-Fu-loaded PLLA microparticles by supercritical fluid technology, Ind. Eng. Chem. Res., 52, pp. 2852-2857.

52. Duarte, A. R. C., Costa, M. S., Simplicio, A. L., Cardoso, M. M. and Duarte, C. M. M. (2006). Preparation of controlled release microspheres using supercritical fluid technology for delivery of anti-inflammatory drugs, Int. J. Pharmaceut., 308, pp. 168-174.

53. Alvarez-Lorenzo, C. and Concheiro, A. (2004). Molecularly imprinted polymers for drug delivery, J. Chromatogr. B, 804, pp. 231-245.

54. Mayes, A. G. and Whitcombe, M. J. (2005). Synthetic strategies for the generation of molecularly imprinted organic polymers, Adv. Drug Deliver. Rev., 57, pp. 1742-1778.

55. Duarte, A. R. C., Casimiro, T., Aguiar-Ricardo, A., Simplicio, A. L. and Duarte, C. M. M. (2006). Supercritical fluid polymerisation and impregnation of molecularly imprinted polymers for drug delivery, J. Supercrit. Fluids, 39, pp. 102-106.

56. da Silva, M. S., Nobrega, F. L., Aguiar-Ricardo, A., Cabrita, E. J. and Casimiro, T. (2011). Development of molecularly imprinted co-polymeric 
devices for controlled delivery of flufenamic acid using supercritical fluid technology, J. Supercrit. Fluids, 58, pp. 150-157.

57. da Silva, M. S., Viveiros, R., Morgado, P. I., Aguiar-Ricardo, A., Correia, I. J. and Casimiro, T. (2011). Development of 2-(dimethylamino)ethyl methacrylate-based molecular recognition devices for controlled drug delivery using supercritical fluid technology, Int. J. Pharmaceut., 416, pp. 6168.

58. Ye, L., Yoshimatsu, K., Kolodziej, D., Francisco, J. D. and Dey, E. S. (2006). Preparation of molecularly imprinted polymers in supercritical carbon dioxide, J. Appl. Polym. Sci., 102, pp. 2863-2867.

59. Kobayashi, T., Leong, S. S. and Zhang, Q. Q. (2008). Using polystyrene-comaleic acid for molecularly imprinted membranes prepared in supercritical carbon dioxide, J. Appl. Polym. Sci., 108, pp. 757-768.

60. Mano, J. F. (2008). Stimuli-responsive polymeric systems for biomedical applications, Adv. Eng. Mater., 10, pp. 515-527.

61. Gil, E. S. and Hudson, S. M. (2004). Stimuli-responsive polymers and their bioconjugates, Prog. Polym. Sci., 29, pp. 1173-1222.

62. Qiu, Y. and Park, K. (2012). Environment-sensitive hydrogels for drug delivery, Adv. Drug Deliver. Rev., 64, pp. 49-60.

63. Hoffman, A. S. (2013). Stimuli-responsive polymers: Biomedical applications and challenges for clinical translation, Adv. Drug Deliver. Rev., 65, pp. 10-16.

64. Alarcon, C. D. H., Pennadam, S. and Alexander, C. (2005). Stimuli responsive polymers for biomedical applications, Chem. Soc. Rev., 34, pp. 276-285.

65. Lehner, R., Wang, X. Y., Wolf, M. and Hunziker, P. (2012). Designing switchable nanosystems for medical application, J. Control. Release, 161, pp. 307-316.

66. Temtem, M., Casimiro, T., Mano, J. F. and Aguiar-Ricardo, A. (2007). Green synthesis of a temperature sensitive hydrogel, Green Chem., 9, pp. 75-79.

67. Duarte, A. R. C., Mano, J. F. and Reis, R. L. (2011). Thermosensitive polymeric matrices for three-dimensional cell culture strategies, Acta Biomater., 7, pp. 526-529.

68. Prabaharan, M. and Mano, J. F. (2006). Stimuli-responsive hydrogels based on polysaccharides incorporated with thermo-responsive polymers as novel biomaterials, Macromol. Biosci., 6, pp. 991-1008.

69. Temtem, M., Barroso, T., Casimiro, T., Mano, J. F. and Aguiar-Ricardo, A. (2012). Dual stimuli responsive poly(N-isopropylacrylamide) coated chitosan scaffolds for controlled release prepared from a non residue technology, J. Supercrit. Fluids, 66, pp. 398-404.

70. Malafaya, P. B., Silva, G. A., Baran, E. T. and Reis, R. L. (2002). Drug delivery therapies II. Strategies for delivering bone regenerating factors, Curr. Opin. Solid State Matter, 6, pp. 297-312. 

and Tissue Engineering Applications

71. Malafaya, P. B., Silva, G. A., Baran, E. T. and Reis, R. L. (2002). Drug delivery therapies I - General trends and its importance on bone tissue engineering applications, Curr. Opin. Solid State Matter, 6, pp. 283-295.

72. Santo, V. E., Gomes, M. E., Mano, J. F. and Reis, R. L. (2012). From nano- to macro-scale: nanotechnology approaches for spatially controlled delivery of bioactive factors for bone and cartilage engineering, Nanomed. UK, 7, pp. 1045-1066.

73. Malafaya, P. B., Silva, G. A. and Reis, R. L. (2007). Natural-origin polymers as carriers and scaffolds for biomolecules and cell delivery in tissue engineering applications, Adv. Drug Deliver. Rev., 59, pp. 207-233.

74. Mano, J. F., Silva, G. A., Azevedo, H. S., Malafaya, P. B., Sousa, R. A., Silva, S. S., Boesel, L. F., Oliveira, J. M., Santos, T. C., Marques, A. P., Neves, N. M. and Reis, R. L. (2007). Natural origin biodegradable systems in tissue engineering and regenerative medicine: present status and some moving trends, J. Royal Soc. Interface, 4, pp. 999-1030.

75. Liu, C., Xia, Z. and Czernuszka, J. T. (2007). Design and development of three-dimensional scaffolds for tissue engineering, Chem. Eng. Res. Des., 85, pp. 1051-1064.

76. Duarte, A. R. C., Mano, J. F. and Reis, R. L. (2009). Perspectives on: supercritical fluid technology for 3D tissue engineering scaffold applications, J. Bioact. Compat. Pol., 24, pp. 385-400.

77. Duarte, A. R. C., Mano, J. F. and Reis, R. L. (2008). Supercritical fluids: an emerging technology for the preparation of scaffolds for tissue engineering, Tissue Eng. Pt. A, 14, pp. 782-782.

78. Cabezas, L. I., Fernandez, V., Mazarro, R., Gracia, I., de Lucas, A. and Rodriguez, J. F. (2012). Production of biodegradable porous scaffolds impregnated with indomethacin in supercritical $\mathrm{CO}_{2}$, J. Supercrit. Fluids, 63, pp. $155-160$.

79. Velasco, D., Benito, L., Fernandez-Gutierrez, M., san Roman, J. and Elvira, C. (2010). Preparation in supercritical $\mathrm{CO}_{2}$ of porous poly(methyl methacrylate)-poly(L-lactic acid) (PMMA-PLA) scaffolds incorporating ibuprofen, J. Supercrit. Fluids, 54, pp. 335-341.

80. Hile, D. D., Amirpour, M. L., Akgerman, A. and Pishko, M. V. (2000). Active growth factor delivery from poly(D,L-lactide-co-glycolide) foams prepared in supercritical $\mathrm{CO}_{2}$, J. Control. Release, 66, pp. 177-185.

81. Nof, M. and Shea, L. D. (2002). Drug-releasing scaffolds fabricated from drug-loaded microspheres, J. Biomed. Mater. Res., 59, pp. 349-356.

82. Kanczler, J. M., Ginty, P. J., White, L., Clarke, N. M. P., Howdle, S. M., Shakesheff, K. M. and Oreffo, R. O. C. (2010). The effect of the delivery of vascular endothelial growth factor and bone morphogenic protein-2 to 
osteoprogenitor cell populations on bone formation, Biomater., 31, pp. 12421250.

83. Kanczler, J. M., Barry, J., Ginty, P., Howdle, S. M., Shakesheff, K. M. and Oreffo, R. O. C. (2007). Supercritical carbon dioxide generated vascular endothelial growth factor encapsulated poly(DL-lactic acid) scaffolds induce angiogenesis in vitro, Biochem. Bioph. Res. Co., 352, pp. 135-141.

84. Duarte, A. R. C., Mano, J. F. and Reis, R. L. (2009). Preparation of chitosan scaffolds loaded with dexamethasone for tissue engineering applications using supercritical fluid technology, Eur. Polym. J., 45, pp. 141-148.

85. Cardea, S., Sessa, M. and Reverchon, E. (2010). Supercritical phase inversion to form drug-loaded poly(vinylidene fluoride-co-hexafluoropropylene) membranes, Ind. Eng. Chem. Res., 49, pp. 2783-2789.

86. Reverchon, E., Cardea, S. and Rappo, E. S. (2006). Production of loaded PMMA structures using the supercritical $\mathrm{CO}_{2}$ phase inversion process, $J$. Membrane Sci., 273, pp. 97-105.

87. Ji, C. D., Barrett, A., Poole-Warren, L. A., Foster, N. R. and Dehghani, F. (2010). The development of a dense gas solvent exchange process for the impregnation of pharmaceuticals into porous chitosan, Int. J. Pharmaceut., 391, pp. 187-196.

88. Silva, S. S., Duarte, A. R. C., Mano, J. F. and Reis, R. L. (2013). Design and functionalization of chitin-based microspheres scaffolds, Green Chem., 15, pp. 3252-3258.

89. Tsioptsias, C., Paraskevopoulos, M. K., Christofilos, D., Andrieux, R. and Panayiotou, C. (2011). Polymeric hydrogels and supercritical fluids: The mechanism of hydrogel foaming, Polymer, 52, pp. 2819-2826.

90. Ji, C. D., Annabi, N., Khademhosseini, A. and Dehghani, F. (2011). Fabrication of porous chitosan scaffolds for soft tissue engineering using dense gas $\mathrm{CO}_{2}$, Acta Biomater., 7, pp. 1653-1664.

91. Singh, M., Sandhu, B., Scurto, A., Berkland, C. and Detamore, M. S. (2010). Microsphere-based scaffolds for cartilage tissue engineering: Using subcritical $\mathrm{CO}_{2}$ as a sintering agent, Acta Biomater., 6, pp. 137-143.

92. Alves, A., Duarte, A. R. C., Mano, J. F., Sousa, R. A. and Reis, R. L. (2012). PDLLA enriched with ulvan particles as a novel 3D porous scaffold targeted for bone engineering, J. Supercrit. Fluids, 65, pp. 32-38. 